\section{Obsessive compulsive disorder in an elderly woman with learning disabilities}

Sir - There have been few case reports or studies of the coexistence of OCD and learning disabilities. People with learning disabilities are increasingly living into old age, but the range of psychiatric disorders that this elderly group experience remains relatively unexplored. Hence we wish to describe the case of an elderly woman with severe learning disabilities who has OCD, and discuss diagnostic criteria for this disorder.

The prevalence of obsessive compulsive disorder (OCD) in the general population is thought to be about $2.5 \%$. However, amongst people with learning disabilities, whilst there have been some case reports of $\mathrm{OCD}^{1,2}$ there are few studies. Vitiello et al assessed the prevalence of repetitive ritualistic behaviour in 283 people with mild to profound learning disabilities, living in a residential setting, and identified 10 residents $(3.5 \%)$ as having compulsive behaviour. ${ }^{3}$ They suggested that the obsessive component could not reliably be assessed and so the emphasis should be on observable behaviour and its consequences. The authors also suggest there are differences in the clinical manifestations of OCD with ordering being the most common compulsion amongst people with learning disabilities, compared to hand washing amongst the general population. Bodfish and Madison developed their ideas, and proposed diagnostic criteria for compulsive behaviour disorder for use with people with learning disabilities, ${ }^{4}$ by adapting DSM-III-R criteria for OCD. The diagnosis requires the presence of compulsive or ritualistic behaviour with the compulsion interfering with training/socialisation, the need for routine/sameness, and socially avoidant, poor response to novelty/change.

The existing literature regarding old age learning disabilities psychiatry is extremely limited. This relates to the fact that, in the past, people with learning disabilities did not usually live into old age. However, life span for people with learning disabilities has increased dramatically, and elderly people with learning disabilities are becoming a numerically significant group within the population. Existing studies show high rates of dementia amongst elderly people with learning disabilities..$^{6-10}$ Although the literature is limited, some other psychiatric conditions have also been reported to occur: depression; ${ }^{8,9,11}$ mania; $;^{8,12}$ schizophrenia; $;, 9,11$ agoraphobia, panic disorder and generalised anxiety disorder ${ }^{8}$ and behaviour disorder. ${ }^{11,13,14}$

It is important to gain an understanding of the range of disorders that are experienced by this group, as this will guide clinical practice and ultimately service development. We have been unable to find any previous reports of OCD occurring in an elderly person with learning disabilities, and hence wish to describe the following individual.

$\mathrm{L}$ is a 74 year old woman with learning disabilities of unknown cause. Vineland Scale (survey form) assessment gave her age equivalent scores for adaptive functioning of communication, three years one month; daily living skills, two years 11 months; socialisation, two years zero months. She was an only child and has no family history of learning disabilities or psychiatric illness. She was born after a normal pregnancy and delivery. Her speech was delayed and she started walking at three years of age. She had no schooling or day care opportunities after the age of eight years. She lived with her family until the 1970 s, when she was introduced to NHS respite care and then longterm care. L has no significant medical history and does not have epilepsy.

L's psychiatric symptoms have been consistently present during her adult life, following a chronic waxing and waning course. She has many personal compulsions, eg. her early morning routine which includes moving pillow cases and pillows in a particular way and opening and shutting the doors, which can last several hours, if not skillfully managed by the nurses. Her mealtime routines include the need for the table to be laid in a particular way, eg. a particular jelly mat and placemat set in a particular exact way, with a certain mug and plate, to avoid distress. If these compulsions are interrupted, she becomes distressed, anxious and screams out. She also demonstrates excessive orderliness and if, for example, the ward furniture is rearranged, she again becomes anxious and screams out, until the matter is resolved. The periods of distress can be prolonged, if the routine is not reinstated, and includes screaming for hours, verbal abuse to others and physical aggression (eg. to other ward residents when they interrupt her mealtime compulsions). As is the case for many people with long-standing $\mathrm{OCD}, \mathrm{L}$ does not appear to resist the rituals. It is not possible to access her obsessional thoughts due to her developmental level.

When $\mathrm{L}$ is not anxious in relation to her compulsions, she can be humorous and relates well to staff, other residents and visitors. She can hold a simple conversation, and enjoys social interaction with others: her social skills are appropriate to her developmental level. She has no cognitive or biological symptoms suggestion of depressive episode, and there has been no decline in her memory, understanding, skills, judgement or thinking to suggest dementia.

Mental state examination reveals her to be an elderly woman who can be co-operative, clean and well dressed. She has good non-verbal communication skills, including eye contact. She has no retardation of facial expression, gesticulation or bodily movements. She is agitated when her rituals are interrupted. She has no stereo-typies. She speaks in short sentences, does not have echolalia, pronoun reversal or repetitive speech. Her affect is consistently euthymic. Her thoughts are normal for rate and form. It is difficult to access details of her abnormal possession of thought, though she demonstrates compulsions. Her content of thought reveals no depressive cognitions. She demonstrates no psychotic phenomena. Cognitively she is orientated for day or night, year, ward and person. Her concentration varies with her degree of agitation but, at her best, it is good. Intellectually, she has severe learning disabilities. Her insight is such that she recognises her distress, agrees to take medication but could not co-operate with a formal response prevention programme. Physical examination, biochemical profile and thyroid function revealed no abnormalities.

It has not been possible to modify her symptoms with behaviour therapy. Pharmacotherapy, including phenthiazines; trazodone $150 \mathrm{mg}$ nocte; fluoxetine $20 \mathrm{mg}$ mane and clomipramine $300 \mathrm{mg}$ nocte, has also proved to be unsuccessful. Higher drug doses have been prohibited by side-effects.

L's psychiatric presentation is that of long-standing 
OCD. The onset was in adolescence, following which there has been a chronic waxing and waning course, which has interfered with her activities and social function. DSM-IV criteria for OCD require evidence of obsessions or compulsions. In the later case, the repetitive behaviour is driven by obsessions and aimed at preventing or reducing distress, they are time consuming, interfere with normal daily activities and relationships and are not due to psychosis, drugs or general medical conditions. The criteria also state that the person at some time, has recognised that the obsessions or compulsions are excessive or unreasonable, except in the case of children. L meets DSM-IV criteria for a diagnosis of OCD except that, due to her developmental level (as in the case of children), it is not possible to determine with confidence that she understands that the compulsions are excessive. L's presentation also meets the criteria for OCD previously proposed for use in people with learning disabilities. ${ }^{4}$

It is not possible to account for L's presentation by any other diagnosis. In particular, she does not meet criteria for depressive episodes, dementia, psychosis or autism. Compulsions can be a symptom of depressions but $\mathrm{L}$ shows no other depressive symptoms which would be necessary to make the diagnosis. Similarly, compulsions can be a symptom of autism, but L does not meet any recognised criteria for autism (eg. DSM-IV or DCR), as she has no other autistic symptoms. In particular, she shows no evidence of impairment in reciprocal social interaction or empathy (which is described as the 'core' abnormality in autistic spectrum disorders ${ }^{15}$ ), impairment in social (verbal or non-verbal) communication, or onset before the age of three years.

The authors hold the view that OCD may be underdiagnosed amongst people with learning disabilities, due to the inappropriate use of the term 'autistic traits' to refer a person with OCD but no other autistic symptoms. Clearly an identical presentation in a person of average ability would not acquire the label 'autistic traits' or 'autism' in the absence of impairments in reciprocal social interaction and social communication. This view may account for the lack of reported studies of OCD in the field of learning disabilities.

Psychiatric illness is often underdiagnosed in people with learning disabilities, despite most psychiatric illnesses being more common in this population. Often long-standing illness is just accepted or labelled as 'behavioural'. The consequence of this is that carers can feel that they have to change to meet the challenge of caring for the person, with the negative result of denying treatment for the individual. Amongst elderly people, carers may attribute symptoms of psychiatric illness to being part and parcel of old age, rather than potentially treatable illness. Accurate diagnosis is important in order to devise appropriate management plans: management and prognosis differs for different disorders.

Unfortunately, this case highlights the difficulty of treatment of OCD in people with learning disabilities. $\mathrm{L}$ did not respond to pharmacotherapy within her limit of tolerance to the medication. It has also not been possible to apply a successful response prevention programme with her cooperation, or a more simple reward based programme. The difficulty of behavioural treatments of OCD in people with learning disabilities, has been previously described. ${ }^{2}$ However, it is important to attempt treatments as these have sometimes been reported to be successful,' and hence the need for accurate diagnosis.

People with learning disabilities are an ageing popula- tion; rate of increase in lifespan is greater for this group than for the general population. However, at present, there is a poor understanding of the psychiatric needs of this population, due to lack of study. This case contributes to existing knowledge in demonstrating that a wide range of psychiatric illness exists in this population. In the case of $\mathrm{L}, \mathrm{a}$ chronic illness has persisted into her old age, and hence her care needs are considerable. Traditionally, specialist health services for people with learning disabilities in the past had a focus on skill acquisition, development and education. Services need to be planned to accommodate the needs of the growing number of elderly, dependent, chronically ill people with learning disabilities.

Julia Middelton, MB, MRCPsych, MRCGP, Associate Specialist in Learning Disabilities, Northern Community Healthcare NHS Trust, Princess Marina Hospital, UPTON, Northampton NN5 6UH, England.

Sally-Ann Cooper, BSc, MRCPsych,
Consultant in Learning Disabilities Psychiatry,
Rockingham Forest NHS Trust,
St Mary's Hospital,
Kettering,
Northants NN15 7 PW,
England.

References

1. O'Dwyer J, Holme J, Collacott R. Obsessive compulsive disorder in Down's syndrome. J Nerv Ment Dis 1992; 180: 603-4.

2. McNally RJ, Calamari JE. Obsessive compulsive disorder in a mentally retarded woman . Br J Psychiatry 1989; 155: 116-7.

3. Vitiello B, Spreat S, Behar D. Obsessive compulsive disorder in mentally retarded patients. J Nervous Ment Dis 1989; 177: 232-5.

4. Bodfish J, Madison J. Diagnosis and fluoxetine treatment of compulsive behaviour disorder of adults with mental retardation. Am J Ment Retard 1993; 98: $360-7$.

5. Cooper SA. The psychiatry of elderly people with mental handicaps. Int J Geriatric Psychiatry 1992; 7: 865-74.

6. Tait D. Mortality and dementia among ageing defectives. J Ment Def Res 1983; $27: 133-42$.

7. Lund J. Epilepsy and psychiatric disorder in the mental retarded adult. Acta Psychiatrica Scandinavica 1985; 72: 557-62.

8. Patel P, Goldberg D, Moss S. Psychiatric morbidity in older people with moderate and severe learning disabilities, II: the prevalence study. $\mathrm{Br}$ J Psychiatry 1993; 163: 481-91.

9. Sansom DT, Singh I, Jawed SH, Mukherjee T. Elderly people with learning disabilities in hospital: a psychiatric study. J Intellect Disabil Res 1994; 38: 45-52. 10. Cooper SA. High prevalence of dementia amongst people with learning disabilities not attributable to Down's syndrome. Psych Med. In Press.

11. Corbett JA. Psychiatric morbidity and mental retardation. In: James FE, Snaith RP, editors. Psychiatric illness and mental handicap. Gaskell Press, 1979: 11-25.

12. Cooper SA, Collacott RA, Hauck A. Late onset mania in Down's syndrome. J Intellec Disabil Res 1994; 38: 73-8.

13. Day K. Psychiatric disorder in the middle-aged and elderly mentally handicapped. Br J Psychiatry 1985; 147: 660-7.

14. Day KA. The elderly mentally handicapped in hospital: a clinical study. J Ment Def Res 1987; 31:131-46.

15. Wing L. The Autistic continuum. In: Aspects of autism: biological research. Wing L, editor. London: Gaskell Press, 1988: v-viii.

\section{Elderly patients presenting with depressive symptoms}

Sir - Lee \& Lawlor's study ${ }^{1}$ of 100 depressed elderly patients found that those with a diagnosis of major depression had a better outcome than patients with comorbid anxiety/depression and dysthymia. This finding requires further exploration, as the identification of patients at risk 